\title{
Assessment of Environmental Factors Influencing Growth and Spread of Pantoea agglomerans on and Among Blossoms of Pear and Apple
}

\author{
K. B. Johnson, V. O. Stockwell, T. L. Sawyer, and D. Sugar
}

First, second, and fourth authors: Department of Botany and Plant Pathology, Oregon State University, Corvallis 97331-2902; and third author: Southern Oregon Research and Extension Center, 569 Hanley Road, Medford 97502.

Accepted for publication 10 August 2000.

\begin{abstract}
Johnson, K. B., Stockwell, V. O., Sawyer, T. L., and Sugar, D. 2000. Assessment of environmental factors influencing growth and spread of Pantoea agglomerans on and among blossoms of pear and apple. Phytopathology 90:1285-1294.

We evaluated effects of both physical and biological components of the environment on growth of Pantoea agglomerans on inoculated pear and apple blossoms and on spread of the bacterium to blossoms on noninoculated trees. The center three rows of 0.35 - to 0.5 -ha blocks of four pear cultivars and four apple cultivars were sprayed with a suspension of streptomycin-resistant $P$. agglomerans strain C9-1S (C9-1S) at 20 to $60 \%$ and 60 to $90 \%$ bloom. Cultivars were chosen to create a sequence of continuous bloom from late March (d'Anjou pear) through mid-May (Red Rome apple). Each cultivar block was quartered into plots; two plots were treated twice with streptomycin sulfate near mid- and full bloom to suppress populations of indigenous bacterial epiphytes and the other two plots were treated with water. Colonization of blossoms by C9$1 \mathrm{~S}$ and by indigenous bacterial epiphytes were monitored on inoculated

inoculated trees. As bloom progressed, trees up to $18 \mathrm{~m}$ from inoculated trees had high proportions of blossoms colonized by C9-1S. Streptomycin significantly $(P \leq 0.05)$ reduced incidence of isolation and size of detectable populations of culturable bacteria (indigenous bacteria plus C9-1S) from pear blossoms in 1998 and from apple blossoms in both 1998 and 1999, but the antibiotic treatment did not affect incidence of isolation, size of detectable populations, or spread of C9-1S compared to the watertreated control in any experiment. Across all cultivars, relative area under the curve for size of detectable populations of C9-1S on inoculated trees and for incidence of isolation of C9-1S from noninoculated trees was positively correlated with mean degree hours per day during bloom $(r=0.61$ to 0.73$)$ and negatively correlated with the proportion of days with rain $(r=-0.79$ to -0.84$)$. The results indicate that establishment and growth of C9-1S on pome fruit flowers was not strongly affected by streptomycin or by competition from indigenous bacterial epiphytes and, as with Erwinia amylovora, temperature is an important environmental variable affecting successful spread of this biological control agent from blossom to blossom.
\end{abstract} trees and along transects of noninoculated trees. Immediately after spraying, C9-1S was detected principally on blossoms sampled from

The blossom blight phase of fire blight of pear and apple, caused by the bacterium Erwinia amylovora, is suppressed when antagonistic bacterial epiphytes, such as Pseudomonas fluorescens or Pantoea agglomerans (synonym: Erwinia herbicola), colonize stigmas of blossoms prior to colonization by the pathogen $(29,35,36)$. In trials conducted over the past 20 years, investigators have shown that one to two applications of a suspension of $P$. agglomerans, Pseudomonas fluorescens, or mixtures of antagonists sprayed onto blossoms reduce the incidence of blossom blight by $\approx 60 \%$ relative to a water-treated control $(7,9,15)$. As a result of these trials, as well as a lack of other effective alternatives $(7,17$, $19,28)$, considerable interest has developed in use of bacterial antagonists as components of an integrated fire blight management program $(7,13,15,25)$.

Effective biological control of fire blight requires that bacterial antagonists of $E$. amylovora colonize the stigmatic surfaces of a large proportion of blossoms and attain population sizes of $10^{4}$ to $10^{6} \mathrm{CFU}$ per blossom $(7,9,35,36)$. Immediately after spraying, populations of antagonistic bacteria typically average $10^{2}$ to $10^{4} \mathrm{CFU}$ on those blossoms open at the time of the application (26). Thus, attainment of an effective population size requires both establishment and growth in blossoms treated directly with the bacterial suspension and also the redistribution (spread) of the antagonists to blossoms that open after the time of treatment (14,

Corresponding author: K. B. Johnson; E-mail address: johnsonk@bcc.orst.edu

Publication no. P-2000-0911-01R

(c) 2000 The American Phytopathological Society
Additional keywords: plant disease epidemiology.

22). Nuclo et al. (22) demonstrated that blossom to blossom spread of bacterial antagonists of E. amylovora can be an important component of disease suppression, but the degree of spread is variable from season to season. The data (22) indicated that temperature influences the process of spread; however, the relationships among temperature, other components of the physical environment, and spread of antagonists were not rigorously explored. Similarly, the biological environment, as represented by indigenous bacterial epiphytes, also may influence growth and spread of applied bacterial antagonists. As an apple or pear blossom opens, bacterial epiphytes are recovered rarely from floral stigmas or hypanthia but, with time, the stigmas can be colonized with high populations of indigenous bacteria (27). Whether or not populations of indigenous bacteria present on the floral surfaces affect colonization and spread of an introduced antagonist has not been investigated. Understanding how physical and biological components of the environment affect establishment, growth, and spread of a bacterial antagonist could lead to improved disease control. Furthermore, knowledge of these processes may be useful for optimizing the timing of biological treatments.

The objective of this study was to evaluate how physical and biological components of the orchard environment affect epiphytic colonization of pear and apple flowers by an introduced strain of Pantoea agglomerans.

\section{MATERIALS AND METHODS}

$P$ agglomerans strain and source. $P$ agglomerans strain C91S (PaC9-1S, synonym Erwinia herbicola strain C9-1S) was ob- 
tained in a commercial, freeze-dried preparation (labeled as BlightBan C9-1) from Plant Health Technologies, Inc. (Boise, ID). This preparation, which had titers of $5.1 \times 10^{10}$ and $2.6 \times$ $10^{10} \mathrm{CFU} \mathrm{g}^{-1}$ in 1998 and 1999 , respectively, was stored at $-50^{\circ} \mathrm{C}$ until use. C9-1S is a spontaneous streptomycin- and rifampicinresistant derivative of $\mathrm{PaC} 9-1$ (25), which was isolated originally from an apple tree in Michigan by C. Ishimaru (Colorado State University, Fort Collins) (6). C9-1S is similar to the parental strain in growth rate and herbicolin production (25).

Experimental design. Field experiments were conducted in four 0.5-ha blocks of pear (Pyrus communis L.) located at the Oregon State University, Southern Oregon Research and Extension Center near Medford and in four 0.35- to 0.4-ha blocks of apple (Malus X domestica Borkh.) located at the Oregon State University, Botany and Plant Pathology Field Laboratory near Corvallis. Each block represented a different cultivar (in one case, adjoining plantings of two apple cultivars) that were selected to create a continuous, 5- to 6-week sequence of bloom, such that the first cultivar (d'Anjou pear) bloomed in late March to early April and the last cultivar (Red Rome apple) completed bloom in midMay (Table 1). At Medford, pear cultivar blocks were adjacent to each other, with trees spaced $8 \mathrm{~m}$ apart within rows and $4 \mathrm{~m}$ apart between rows. At Corvallis, apple cultivar blocks were separated from each other by 50 to $200 \mathrm{~m}$ of open field; trees were spaced $6 \mathrm{~m}$ apart within and between rows. Ages of the cultivar blocks ranged from 3 to 45 years old (Table 1).

Each cultivar block was quartered into plots with one streptomycin-treated and one water-treated plot placed randomly on each side of a centerline that bisected the blocks (Fig. 1). For the Jonathan or Red Delicious block, the quartering resulted in two plots that were $100 \%$ Jonathan, one treated with streptomycin and the other water, and two plots that were $100 \%$ Red Delicious, assigned similarly. Streptomycin sulfate (Agristrep 17\%, $100 \mathrm{mg}$ a.i. liter $^{-1}$, Novartis Crop Protection, Greensboro, NC) or water (groundwater source) were applied to plots at 50 to $90 \%$ and again at $80 \%$ to full bloom (Table 1). In Medford, an airblast sprayer was used to apply the antibiotic and water treatments at a rate of 4 liters per tree. In Corvallis, streptomycin and water treatments were applied with a motorized tank sprayer equipped with handgun; spray volume ranged from 2 to 4 liters per tree, depending on tree size. Treatments of streptomycin and water were made either in early morning or near sunset under still wind conditions. At both locations, a beehive was placed in each cultivar block at 5 to $20 \%$ bloom following standard commercial practice. Also at both locations, a routine application of fungicide (fenarimol) was applied to each cultivar block during the experimental period to control apple or pear scab (Venturia inequalis and $V$. pirina, respectively).
C9-1S was introduced to all cultivar blocks by inoculating the 15 to 24 trees in the center three rows (Fig. 1) at 20 to $60 \%$ bloom and again at 60 to $90 \%$ bloom (Table 1) with a suspension of the antagonist prepared from the freeze-dried inoculum to a final concentration of $1 \times 10^{8} \mathrm{CFU} \mathrm{ml}{ }^{-1}$. The bacterial suspension was applied with a tank sprayer equipped with handgun to near runoff, which amounted to 2 to 4 liters of suspension per tree, depending on tree size. The timings of C9-1S inoculations represented the current recommended practice for commercial application of bacterial antagonists for fire blight suppression. All inoculations of C9-1S were made between 6:00 and 7:30 a.m. under still wind conditions to minimize drift of the sprayed suspension (22).

Environmental monitoring. Weather variables, including temperature and rainfall, were monitored continuously with automated weather stations located on the experimental sites. Each station was part of a satellite-based network of agricultural weather stations operated and maintained by the U.S. Bureau of Reclamation (Agrimet Weather Network, U.S. Bureau of Reclamation, Pacific Northwest Region, Boise, ID). Data recorded every $15 \mathrm{~min}$ were used in the analyses described below. Also, on several dates after full bloom, insect foraging on pear and apple blossoms (principally by honey bees) was observed in each cultivar block using methods described previously (8).

Sampling to monitor colonization of blossoms by C9-1S. In all cultivars, apple or pear blossoms were sampled on the day of inoculation with C9-1S and every 3 to 5 days thereafter from one inoculated and three noninoculated trees in each plot. Sampled trees were located immediately adjacent to each other along a transect that ran through the center of each plot perpendicular to the rows of trees treated with C9-1S (Fig. 1). Eight mature blossoms (dark anthers) were collected at random from each tree on each sample date. Blossoms were placed into individual wells of sterile microtiter plates and transported to the lab in a cooler. Each cultivar block was sampled on four to seven dates, beginning near $50 \%$ bloom and ending at petal fall (Table 1).

In the laboratory, incidence of isolation and size of detectable populations of culturable bacteria (indigenous bacterial epiphytes plus C9-1S) and of C9-1S only on the pistils of individual blossoms were determined by dilution plating blossom washes onto media by methods described previously $(8,9,22,25-27)$. Pseudomonas Agar F (Difco Laboratories, Detroit) (11) amended with cycloheximide (PAF) at $50 \mathrm{mg} \operatorname{liter}^{-1}$ was used to isolate culturable bacteria. PAF amended with rifampicin at $50 \mathrm{mg} \mathrm{liter}^{-1}$ and streptomycin at $100 \mathrm{mg} \mathrm{liter}^{-1}$ was used for selective recovery of C9-1S (25). After every eighth blossom, a set of dilution tubes containing only sterile phosphate buffer was plated similarly as controls. Bacterial colonies were counted after incubation for 3 to 4 days at 20 to $24^{\circ} \mathrm{C}$. The detection limit of the dilution plating

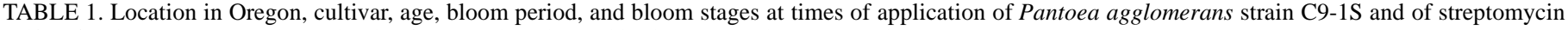
sulfate for the 0.35- to 0.50-ha orchards of pear and apple used in the 1998 and 1999 experiments

\begin{tabular}{|c|c|c|c|c|c|c|c|}
\hline \multirow[b]{2}{*}{ Location, cultivar } & \multirow[b]{2}{*}{ Planted $^{\mathrm{a}}$} & \multicolumn{3}{|c|}{1998} & \multicolumn{3}{|c|}{1999} \\
\hline & & Period $^{b}$ & C9-1S $(\%)^{\mathrm{c}}$ & Strep and water $(\%)^{\mathrm{d}}$ & Period & C9-1S (\%) & Strep and water $(\%)$ \\
\hline \multicolumn{8}{|l|}{ Medford (pear) } \\
\hline d'Anjou & 1963 & $26 \mathrm{Mar}$ to $17 \mathrm{Apr}$ & 40,90 & 60 , full & 2 to $26 \mathrm{Apr}$ & 50,90 & 80 , full \\
\hline Bartlett & 1963 & $28 \mathrm{Mar}$ to $21 \mathrm{Apr}$ & 30,80 & 60 , full & 4 to $26 \mathrm{Apr}$ & 50,80 & 50,90 \\
\hline Comice & 1963 & 6 to $28 \mathrm{Apr}$ & 30,80 & 70 , full & 16 to $28 \mathrm{Apr}$ & 60,90 & 90 , full \\
\hline Bosc & 1963 & 7 to $28 \mathrm{Apr}$ & 25,75 & 50,85 & 17 to $28 \mathrm{Apr}$ & 30,80 & 80, full \\
\hline \multicolumn{8}{|l|}{ Corvallis (apple) } \\
\hline Braeburn & 1995 & 15 Apr to 1 May & 30,70 & 60,90 & 21 Apr to 10 May & 20,70 & 30,80 \\
\hline Golden Delicious & 1979 & $16 \mathrm{Apr}$ to $26 \mathrm{Apr}$ & 25,60 & 50,90 & 24 Apr to 13 May & 20,80 & 50,90 \\
\hline Jonathan/Red Delicious & 1954 & 16 Apr to 1 May & 40,70 & 60 , full & 22 Apr to 10 May & 40,80 & 60 , full \\
\hline Red Rome & 1958 & 22 Apr to 7 May & 40,80 & 60 , full & 30 Apr to 19 May & 20,80 & 60 , full \\
\hline
\end{tabular}

a Year block planted.

b First bloom to petal fall.

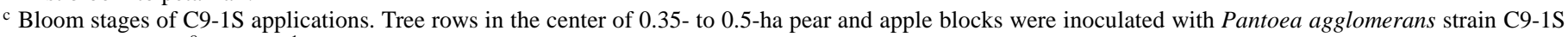
at a rate of $1 \times 10^{8} \mathrm{CFU} \mathrm{ml}-1$ with 2 to 4 liters applied to each tree depending on size.

${ }^{\mathrm{d}}$ Bloom stages of streptomycin sulfate or water, applied at a rate of $100 \mathrm{mg}^{\mathrm{a} . \mathrm{i}}$. liter ${ }^{-1}$ with 2 to 4 liters applied to each tree depending on size. 
procedure was $1 \times 10^{2} \mathrm{CFU}$ per blossom. Over both seasons, 10,240 blossoms were washed and plated in this manner. Only bacterial colonies with size, color, morphology, and growth rate consistent with C9-1S were recovered on the rifampicin- and streptomycin-amended PAF medium.

Data analysis. Incidence of isolation of culturable bacteria and of C9-1S were determined for each sampled tree on each sample date. Mean population size of detectable culturable bacteria and of detectable C9-1S per tree were determined similarly; however, estimates of bacterial population size on individual blossoms were first transformed to $\log _{10}(\mathrm{x})(5,17)$, and blossoms on which culturable bacteria or C9-1S were not detected were excluded from the mean (26 describes rationale of this method of handling bacterial population data).

Incidence of isolation and population size data were first summarized by averaging within year, host (apple or pear), and bloom stage the values from trees with similar plot positions. Labels for plot position were inoculated trees $(I)$, noninoculated trees located immediately adjacent ( 4 to $6 \mathrm{~m}$ ) to the inoculated row $\left(N_{1}\right)$, noninoculated trees located two rows ( 8 to $12 \mathrm{~m}$ ) from the inoculated row $\left(N_{2}\right)$, and most distal noninoculated trees $\left(N_{3}\right)$, which was located three rows (12 to $18 \mathrm{~m}$ ) from the inoculated row. Bloom stages used for averaging were 50\%, 90\%, full bloom, and petal fall (calendar dates corresponding to the bloom stages differed among some cultivars, as did the number of days between bloom stages). Incidence of isolation and mean size of detectable populations of C9-1S on trees at different plot positions were plotted in temporal arrays as a function of bloom stage. Similarly, incidence of isolation and mean size of detectable populations of culturable bacteria and of C9-1S on trees at specific bloom stages were plotted in spatial arrays as a function of plot position. Data summarized by plot position and bloom stage also were subjected to analysis of variance (ANOVA) to determine if treatment with streptomycin affected the bacterial response variables. Separate ANOVA analyses were conducted for each plot position and bloom stage, with cultivars representing blocks within a random-

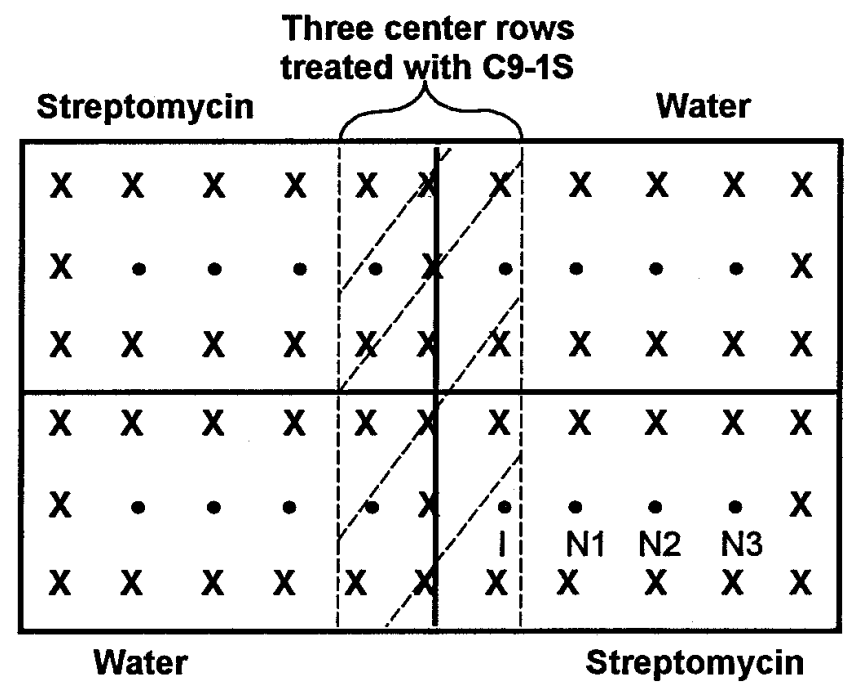

Fig. 1. Experimental design used in 0.35- to 0.50-ha blocks of four apple and of four pear cultivars in 1998 and 1999. Each cultivar block was quartered into two streptomycin-treated and two water-treated plots. The three rows across the center of the plot were inoculated with Pantoea agglomerans strain C9-1S at 20 to $60 \%$ and again at 60 to $90 \%$ bloom. Circles represent trees that were sampled to monitor bacterial populations on floral surfaces, and Xs represent nonsampled border trees. Plot in lower right shows labels used to designate proximity of sampled trees to trees treated with C9-1S: $I=$ inoculated tree, $N_{1}=$ noninoculated tree located immediately adjacent $(4$ to $6 \mathrm{~m})$ to the inoculated row, $N_{2}=$ noninoculated tree located two rows ( 8 to $12 \mathrm{~m}$ ) from the inoculated row, and $N_{3}=$ noninoculated tree located three rows (12 to $18 \mathrm{~m}$ ) from the inoculated row. ized block design. The null hypotheses that treatment with streptomycin had no effect on incidence of isolation or mean size of detectable populations of culturable bacterial and of C9-1S were evaluated at $P$ values of $0.10,0.05$, and 0.01 .

The second approach to data analysis compared C9-1S response variables to the weather conditions experienced during each bloom period. Initially, incidence of isolation and mean size of detectable populations of C9-1S averaged within year, cultivar, plot position, and sampling date were compared to daily mean temperature and daily rainfall amount in temporal arrays. Area under curve for incidence of isolation $\left(A_{\text {inc }}\right)$ and for mean size of detectable populations $\left(A_{\text {pop }}\right)$ of $\mathrm{C} 9-1 \mathrm{~S}$ were calculated for each cultivar and plot position in each season:

$$
A=\left[\sum_{i=2}^{n}\left(y_{i}+y_{i-1}\right) / 2 \cdot\left(t_{i}-t_{i-1}\right)\right] /\left(t_{n}-t_{1}\right)
$$

where $y$ and $t$ are the value of the bacterial response variable and day of year, respectively, for the ith sample date, and $n$ is the total number of sample dates during the bloom period. Corresponding to the bloom period of each cultivar (i.e., $t_{1}$ to $t_{n}$ ), rainfall data were summarized as proportion of days with rain and temperature data were summarized by computing mean degree hours per day. Degree hours were computed using base temperatures of $8,10,12.5$, 15 , and $18^{\circ} \mathrm{C}$. Values of $A_{\text {inc }}$ for all cultivar blocks were combined into a single data set and subjected to simple linear regression using mean degree hours per day or proportion of days with rain as independent variables. Values of $A_{\text {pop }}$ were regressed similarly.

\section{RESULTS}

Temporal development of C9-1S populations. In both seasons, C9-1S established on a high proportion of open blossoms inoculated directly with the spray suspension. At $50 \%$ bloom, the incidence of isolation of C9-1S from inoculated trees averaged

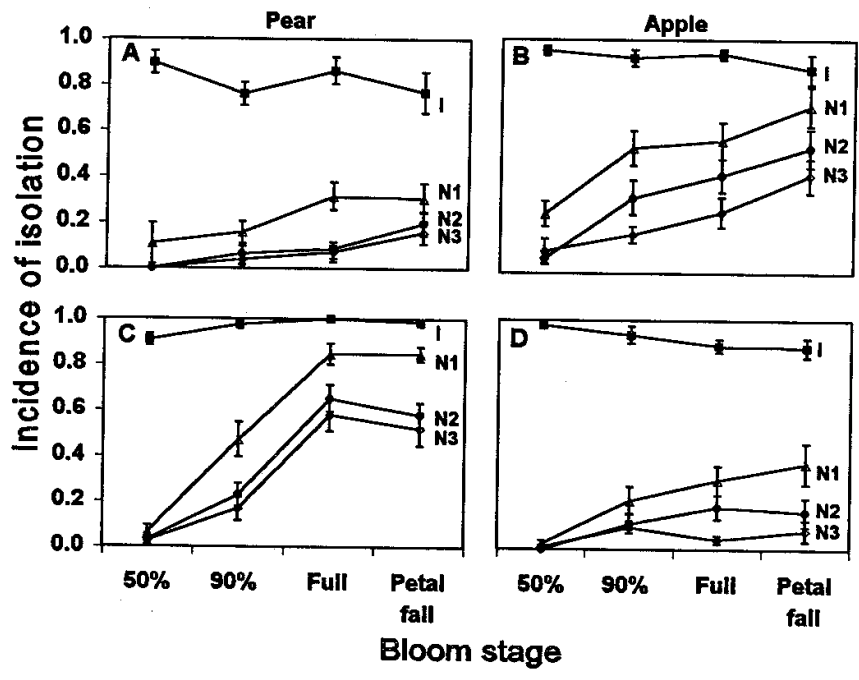

Fig. 2. Mean incidence of isolation of Pantoea agglomerans strain C9-1S on blossoms of $\mathbf{A}$ and $\mathbf{C}$, pear and $\mathbf{B}$ and $\mathbf{D}$, apple at bloom stages of 50\%, 90\%, full bloom, and petal fall for experiments conducted in four cultivar blocks of each host species during 1998 (upper panels) and 1999 (lower panels). Each point represents the mean of 128 blossoms sampled from four trees of each of the four cultivars ( 8 blossoms per tree). Line and points $I=$ blossoms sampled from trees inoculated with $\mathrm{C} 9-1 \mathrm{~S}$ at 20 to $60 \%$ and again at 60 to $90 \%$ bloom; $N=$ noninoculated trees located immediately adjacent ( 4 to $6 \mathrm{~m}$ ) to the inoculated row $\left(N_{1}\right)$, noninoculated tree located two rows $(8$ to $12 \mathrm{~m}$ ) from the inoculated row $\left(N_{2}\right)$, and noninoculated tree located three rows (12 to $18 \mathrm{~m})$ from the inoculated row $\left(N_{3}\right)$. Length of the bloom periods $(50 \%$ bloom to petal fall) were 18 to 20 days for pear in 1998,10 to 12 days for apple in 1998, 10 days for pear in 1999, and 14 to 17 days for apple in 1999. Vertical lines drawn through points represent plus and minus one standard error of the mean. 
$>90 \%$ in all experiments (Fig. 2). This high incidence of isolation on blossoms sampled from inoculated trees was generally maintained through the bloom period of all experiments, except for pear in 1998, when only $77 \%$ of blossoms from inoculated trees had detectable populations of C9-1S at petal fall. Measured sizes of detectable populations of C9-1S on blossoms of inoculated trees showed temporal patterns consistent with reproduction of this antagonist on floral surfaces. Initial detectable population sizes were in the range of $1 \times 10^{3}$ to $1 \times 10^{5} \mathrm{CFU}$ per blossom (Fig. 3). Sizes of detectable populations of C9-1S on inoculated trees increased during bloom in all experiments, with populations at petal fall exceeding $1 \times 10^{6} \mathrm{CFU}$ per blossom for apple in 1998 and pear in 1999 but only attaining a mean of $\approx 1 \times 10^{5}$ CFU per blossom for pear in 1998 and apple in 1999.

For noninoculated trees, C9-1S was detected at low frequency from blossoms sampled early in the bloom period, but the incidence of isolation of the antagonists generally increased as bloom progressed (Fig. 2). Incidences of isolation of C9-1S were consistently higher from noninoculated trees in the row adjacent to the inoculated row $\left(N_{1}\right)$ than from noninoculated trees in the two rows more distal $\left(N_{2}\right.$ and $\left.N_{3}\right)$. Across all noninoculated trees $\left(N_{1}\right.$ to $N_{3}$ ), incidences of isolation of C9-1S at petal fall averaged 56 and $65 \%$ for apple in 1998 and pear in 1999, respectively, but only $21 \%$ at this same bloom stage for pear in 1998 and for apple in 1999. Similar to the incidence of isolation data, the size of detectable populations of $\mathrm{C} 9-1 \mathrm{~S}$ in blossoms sampled from noninoculated trees increased during the bloom period, but the mean sizes were consistently about one log unit smaller than means obtained from inoculated trees (Fig. 3). Only rarely did the mean size of detectable populations of $\mathrm{C} 9-1 \mathrm{~S}$ on noninoculated trees exceed $1 \times 10^{5}$ CFU per blossom.

Effect of streptomycin on bacterial epiphyte populations. Streptomycin sulfate was applied to plots to suppress populations

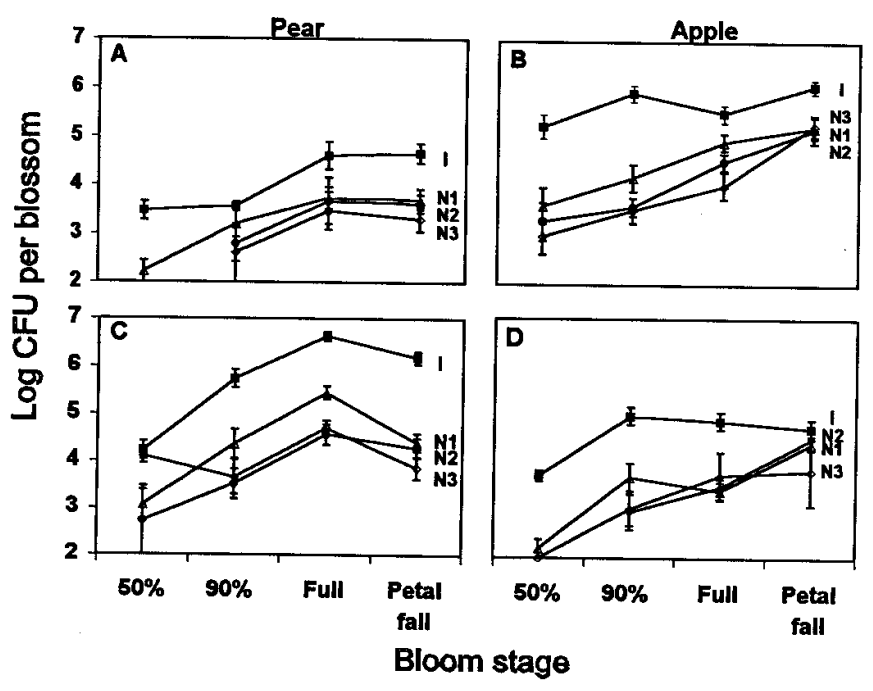

Fig. 3. Mean size of detectable populations of Pantoea agglomerans strain C9-1S on blossoms of $\mathbf{A}$ and $\mathbf{C}$, pear and $\mathbf{B}$ and $\mathbf{D}$, apple at bloom stages of $50 \%, 90 \%$, full bloom, and petal fall for experiments conducted in four cultivar blocks of each host species during 1998 (upper panels) and 1999 (lower panels). Each point represents the mean population on the proportion of the 128 sampled blossoms on which C9-1S was detected (blossoms sampled from four trees of each of the four cultivars, 8 blossoms per tree). Line and points $I=$ blossoms sampled from trees inoculated with C9-1S at 20 to $60 \%$ and again at 60 to $90 \%$ bloom; $N=$ noninoculated trees located immediately adjacent (4 to $6 \mathrm{~m}$ ) to the inoculated row $\left(N_{1}\right)$, noninoculated tree located two rows $(8$ to $12 \mathrm{~m})$ from the inoculated row $\left(N_{2}\right)$, and noninoculated tree located three rows (12 to $18 \mathrm{~m})$ from the inoculated row $\left(N_{3}\right)$. The length of the bloom periods ( $50 \%$ bloom to petal fall) were 18 to 20 days for pear in 1998,10 to 12 days for apple in 1998, 10 days for pear in 1999, and 14 to 17 days for apple in 1999. Vertical lines drawn through points represent plus and minus one standard error of the mean. of indigenous bacterial epiphytes. Compared with water-treated plots, incidence of isolation of culturable bacteria (indigenous bacteria plus C9-1S) and size of detectable populations of culturable bacteria were reduced significantly for the pear experiment in 1998 and for the apple experiments in both seasons, but not for the pear experiment in 1999 (Table 2). Treatment with streptomycin did not eliminate culturable bacteria other than C9-1S from sampled blossoms, but the treatment increased the ratios of incidence of isolation and of size of detectable populations of C9-1S to culturable bacteria. For example, for the period between $90 \%$ bloom and petal fall of pear in 1998 and of apple in 1998 and 1999, ratios of incidence of isolation of C9-1S to culturable bacteria on water-treated blossoms sampled from noninoculated trees averaged $0.15,0.54$, and 0.35 , respectively, and were increased to $0.32,0.64$, and 0.56 , respectively, in plots treated with streptomycin. Similarly, for the same period of bloom of pear in 1998 and of apple in 1998 and 1999, ratios of measured sizes of detectable populations of C9-1S to culturable bacteria on water-treated blossoms sampled from noninoculated trees averaged $0.79,0.89$, and 0.90 , respectively, and were increased to $0.84,0.97$, and 1.00, respectively, in streptomycin-treated plots. In contrast to the observed reductions in incidence of isolation and size of detectable populations of culturable bacteria, treatment with streptomycin did not affect either the incidence of isolation or the size of detectable populations of C9-1S on inoculated or noninoculated trees in any experiment (Table 2). The contrasting effects of streptomycin on culturable bacteria and on C9-1S also were apparent when the data were plotted in spatial arrays (Fig. 4).

Relationships between weather variables and populations of C9-1S. The years 1998 and 1999 provided a dichotomous contrast in weather conditions during the experimental period. Pear bloom of 1998 was cool with frequent rain (mean daily temperature of $8.6^{\circ} \mathrm{C}$ with measurable rain on $60 \%$ of days from 27 March to 28 April), whereas apple bloom in 1998 was characterized by warm temperatures with infrequent rain (mean daily temperature of $14.1^{\circ} \mathrm{C}$ with rain on $23 \%$ of days from 18 April to 7 May). Conversely, 1999 had warm temperatures with few periods of rain during pear bloom (mean daily temperature of $12.4^{\circ} \mathrm{C}$ with rain on $6 \%$ of days from 15 to 28 April) and cooler temperatures with frequent rain during apple bloom (mean daily temperature of $9.1^{\circ} \mathrm{C}$ with rain on $69 \%$ of days from 22 April to 20 May). Over the 5- to 6-week bloom period in each season, graphical arrays depicting temporal variation in the size of detectable populations of C9-1S on inoculated trees and in the incidence of isolation of C9-1S from noninoculated trees appeared to show positive associations with mean daily temperature and negative associations with periods of frequent rain (Fig. 5). These associations (i.e., that C9-1S response variables were related positively with temperature and negatively with frequency of rain) were significant $(P \leq 0.05)$ when relative area under curve for size of detectable populations of C9-1S on inoculated trees was regressed on mean degree hours per day and on proportion of days with rain (Fig. 6A and B). A similar result was obtained when area under the curve for incidence of isolation of $\mathrm{C} 9-1 \mathrm{~S}$ from noninoculated trees was regressed on the temperature and rainfall variables (Fig. 6C to F). In the regression relationships, the choice of base temperature for determination of daily degree hours per day did not influence the relative patterns of the data points or the significance of the regression parameters. Values for the coefficient of determination (percentage of variation explained), however, declined somewhat ( 2 to $12 \%$ ) as the degree hour base temperature was increased from 8 to $18^{\circ} \mathrm{C}$.

\section{DISCUSSION}

To achieve biological control of fire blight, bacterial antagonists such as C9-1S must establish and grow on blossoms inoculated directly with the bacterial suspension and also spread secondarily 
from colonized blossoms to noncolonized blossoms, including those where initial establishment was unsuccessful and those that open after the time of treatment $(14,22)$. Each of these processes (establishment, growth, and spread) contributes to the degree of disease control obtained, but each process can be variable among orchards and season $(8,22,26)$. Previously, we demonstrated that the initial establishment of antagonists on blossoms can be affected by the method of inoculum preparation, by environmental conditions at the time of inoculation (26), and by the compatibility of antagonists with chemicals used for fire blight suppression (25). In this study, our goal was to extend the understanding of sources of variation affecting an antagonist population to factors influencing its growth and redistribution after initial establishment. In this regard, we obtained evidence that temperature was important to the attainment of a large, spreading population of C9$1 \mathrm{~S}$, but that use of a broad spectrum antibiotic, streptomycin, to suppress potential indigenous competitors had little impact on either growth or redistribution of the selected antagonist strain.

The use of multiple cultivar blocks of pear and apple that bloomed sequentially over a 5- to 6-week period provided a range of weather conditions from which the effects of the physical and biological environment on growth and spread of C9-1S could be assessed. Among seasons, the temporal patterns of spring weather were surprisingly dichotomous, such that relatively cool, rainy conditions dominated bloom of pear in 1998 and of apple in 1999, and warm, dry conditions prevailed during bloom of apple in 1998 and of pear in 1999 (Fig. 5). This dichotomy of cool-wet and warm-dry weather patterns that occurred in opposite order between the two seasons allowed us to observe a similar range of environmental conditions on both pear and apple. As a result, the regression relationships between $\mathrm{C} 9-1 \mathrm{~S}$ and weather variables indicated that the environmental conditions exerted consistent effects on growth and redistribution of the antagonist, and that these effects were not influenced greatly by the host plant.
On trees inoculated with the antagonist suspension, C9-1S became established on $>90 \%$ of blossoms in all cultivar blocks. Factors that likely contributed to high establishment rates were the use of freeze-dried inoculum, inoculation at a time of day when the drying time of sprayed suspensions was relatively slow (early morning) (26), and inoculation at two stages of bloom, which is our current recommendation for use of bacterial antagonists for fire blight suppression (7). The resulting detectable populations of C9-1S on inoculated trees were of sufficient sizes $\left(10^{4}\right.$ to $10^{6} \mathrm{CFU}$ per blossom) to suppress epiphytic growth of E. amylovora (9). In contrast, on noninoculated trees, the frequency of establishment of C9-1S on blossoms, as measured by incidence of isolation, varied between seasons. At petal fall, C9-1S was recovered at a high incidence $(60 \%)$ from noninoculated trees of apple in 1998 and of pear in 1999 , but this response variable averaged only $21 \%$ for noninoculated trees of pear in 1998 and of apple in 1999. Similarly, mean sizes of detectable populations of C9-1S on blossoms from noninoculated treated trees were consistently smaller $(\approx 10$ fold) than population sizes measured on inoculated trees. With regard to disease suppression, these differences in establishment rates and sizes of detectable populations of C9-1S among inoculated and noninoculated trees suggests that direct spray inoculation of all trees in an orchard with an antagonist suspension will likely be superior to other possible strategies of antagonist introduction, such as alternate row spraying or inoculation of honey bees with dust formulations of antagonists as they exit their hive $(8,30,34)$. Our data does not, however, provide insight into whether or not the same levels of establishment on the inoculated trees could have been achieved with one antagonist application as opposed to the two applications made in this study.

Streptomycin was included as a treatment to evaluate whether or not indigenous bacterial epiphytes influence the population dynamics of $\mathrm{C} 9-1 \mathrm{~S}$ and, if so, to minimize a source of variation that could potentially confound the analysis of other environ-

TABLE 2. Comparison of treatment of pear and apple orchards with streptomycin sulfate or water on incidence of isolation and of population size of total culturable bacteria and of Pantoea agglomerans strain C9-1S on pear blossoms at Medford, OR and apple blossoms at Corvallis, OR during 1998 and $1999^{a}$

\begin{tabular}{|c|c|c|c|c|c|c|c|c|c|c|c|c|c|c|}
\hline \multirow[b]{3}{*}{ Host, year } & \multirow[b]{3}{*}{ Bloom stage } & \multirow[b]{3}{*}{ Treatment $^{\mathrm{b}}$} & \multicolumn{6}{|c|}{ Incidence of isolation of } & \multicolumn{6}{|c|}{ Size of detectable population of } \\
\hline & & & \multicolumn{3}{|c|}{ Culturable bacteria $^{\mathrm{c}}$} & \multicolumn{3}{|c|}{ C9-1S } & \multicolumn{3}{|c|}{ Culturable bacteria } & \multicolumn{3}{|c|}{ C9-1S } \\
\hline & & & $N_{1}{ }^{\mathrm{d}}$ & $N_{2}$ & $N_{3}$ & $N_{1}$ & $N_{2}$ & $N_{3}$ & $N_{1}$ & $\mathrm{~N}_{2}$ & $N_{3}$ & $N_{1}$ & $\mathrm{~N}_{2}$ & $N_{3}$ \\
\hline \multirow[t]{4}{*}{ Pear, 1998} & Full & Water & $0.92 * *$ & $0.91 * *$ & $0.94 * * *$ & 0.35 & 0.19 & 0.24 & $4.9 * *$ & $4.7 *$ & 4.7 & 3.6 & 3.4 & 3.6 \\
\hline & & Streptomycin & 0.71 & 0.80 & 0.63 & 0.36 & 0.22 & 0.14 & 4.2 & 4.0 & 4.0 & 3.9 & 3.6 & 3.1 \\
\hline & Petal-fall & Water & 0.85 & $0.77 * *$ & $0.89 * *$ & 0.25 & 0.20 & 0.17 & 4.6 & $5.0^{*}$ & 4.7 & 3.6 & 3.6 & 3.6 \\
\hline & & Streptomycin & 0.69 & 0.66 & 0.72 & 0.36 & 0.19 & 0.14 & 4.3 & 4.1 & 3.8 & 3.8 & 3.6 & 2.7 \\
\hline \multirow[t]{4}{*}{ Pear, 1999} & Full & Water & 0.99 & 0.96 & 0.99 & 0.80 & 0.66 & 0.55 & 5.9 & 5.5 & 5.5 & 5.7 & 4.7 & 4.6 \\
\hline & & Streptomycin & 1.00 & 0.99 & 0.97 & 0.89 & 0.64 & 0.61 & 5.7 & 5.5 & 5.7 & 5.2 & 4.4 & 4.9 \\
\hline & Petal-fall & Water & 0.96 & 0.94 & 0.95 & $0.79 *$ & 0.60 & 0.49 & 5.2 & 5.1 & 5.0 & 4.2 & 4.3 & 3.7 \\
\hline & & Streptomycin & 0.99 & 0.91 & 1.00 & 0.91 & 0.57 & 0.55 & 5.5 & 5.3 & 5.3 & 4.6 & 4.2 & 4.0 \\
\hline \multirow[t]{4}{*}{ Apple, 1998} & Full & Water & $0.95^{* *}$ & 0.84 & $0.97 * *$ & 0.61 & 0.38 & 0.25 & $5.2^{* *}$ & $5.2 *$ & $5.0^{* *}$ & 5.0 & 4.4 & 3.9 \\
\hline & & Streptomycin & 0.77 & 0.68 & 0.60 & 0.52 & 0.46 & 0.27 & 4.5 & 4.4 & 3.9 & 4.9 & 4.7 & 4.2 \\
\hline & Petal-fall & Water & 0.92 & $0.97 * * *$ & $0.92 * *$ & 0.71 & 0.52 & 0.44 & $5.7^{*}$ & 5.2 & 5.4 & 5.3 & 5.1 & 5.2 \\
\hline & & Streptomycin & 0.80 & 0.68 & 0.61 & 0.72 & 0.55 & 0.39 & 5.2 & 5.4 & 4.9 & 5.3 & 5.3 & 5.4 \\
\hline \multirow[t]{4}{*}{ Apple, 1999} & Full & Water & $0.63^{* * *}$ & $0.57 * *$ & $0.66^{* * *}$ & 0.29 & 0.23 & 0.08 & 4.4 & $4.1^{* *}$ & 4.1 & 4.2 & 3.6 & 3.2 \\
\hline & & Streptomycin & 0.27 & 0.24 & 0.15 & 0.16 & 0.20 & 0.07 & 4.2 & 3.6 & 4.1 & 5.2 & 3.5 & 3.7 \\
\hline & Petal-fall & Water & $0.82 * *$ & $0.83^{* *}$ & $0.61 * *$ & 0.36 & 0.16 & 0.15 & 4.9 & $4.4^{* *}$ & 4.8 & 4.5 & 4.2 & 4.2 \\
\hline & & Streptomycin & 0.48 & 0.33 & 0.24 & 0.39 & 0.16 & 0.02 & 4.4 & 3.9 & 3.9 & 4.3 & 4.8 & 2.5 \\
\hline
\end{tabular}

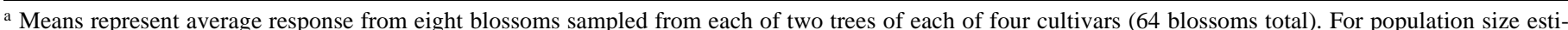
mates, blossoms on which culturable bacteria or C9-1S were not detected were excluded from the mean. A separate analysis of variance was conducted for each pair of water and streptomycin responses. $*=$ Difference between water and streptomycin treatment significant at $P=0.10$; $* *=$ difference between water and streptomycin treatment significant at $P=0.05$; and $* * *=$ difference between water and streptomycin treatment significant at $P=0.01$.

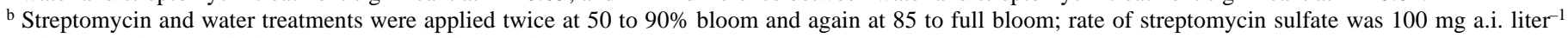
with 2 to 4 liters applied to each tree depending on size.

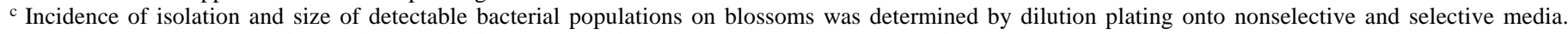
Culturable bacteria was defined as isolated indigenous bacteria plus Pantoea agglomerans strain C9-1S.

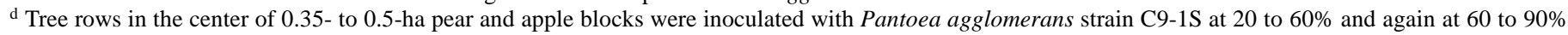
bloom. Blossoms were sampled from noninoculated trees located immediately adjacent ( 4 to 6 m) to the inoculated row $\left(N_{1}\right)$, noninoculated trees located two rows $\left(8\right.$ to $12 \mathrm{~m}$ ) from the inoculated row $\left(N_{2}\right)$, and noninoculated trees located three rows (12 to $\left.18 \mathrm{~m}\right)$ from the inoculated row $\left(N_{3}\right)$. 
mental relationships. In this regard, we conclude that the streptomycin treatment was partially successful. The variable, incidence of isolation of culturable bacteria, was affected more strongly by the streptomycin treatment than was the corresponding variable representing size of detectable populations, indicating that the chemical may influence establishment of bacteria on blossoms more than it suppresses growth of established colonies. This is a result we have observed previously in the evaluation of the effect of oxytetracycline on establishment and growth of C9-1S, E. amylovora, and Pseudomonas fluorescens on apple flowers (25). On average, the streptomycin treatment had a greater effect in the apple experiments conducted in Corvallis than in the pear experiments in Medford. In a previous survey of bacterial epiphytes of pear flowers (27), resistance to streptomycin was common for indigenous bacterial epiphytes recovered from pear blossoms in Medford but not common in those obtained in Corvallis (V. Stockwell, unpublished data). As part of the present study, we confirmed the earlier observations by streaking isolated bacterial epiphytes on a streptomycin-amended medium (data not shown). The reason for these geographic differences in frequency of streptomycin resistance among isolated bacterial epiphytes may relate to the proximity of each experimental site to commercial fruit production. In Medford, the experimental orchards were located within a 3,500-ha pear production region where streptomycin has been used to suppress fire blight for approximately 40 years. Conversely, the experimental apple trees in Corvallis were geographically isolated from commercial orchards, and these trees had not been treated with streptomycin previously as part of routine disease management activities.

Although significant reductions of incidence of isolation and of size of detectable populations of culturable bacteria could be attributed to use of streptomycin, the antibiotic treatment had no effect on either incidence of isolation or size of detectable populations of C9-1S. Nuclo (21) and Stockwell (unpublished data), in replacement series experiments, both observed that growth of C9-1S on pear blossoms was not suppressed by coinoculation with a second bacterial antagonist, $P$. fluorescens strain A506. In this study, the majority of indigenous bacteria isolated from blossoms were characteristic of fluorescent pseudomonads (27) and only rarely were they characteristic of other strains of Pantoea agglomerans. Thus, establishment and growth of C9-1S on pear and apple blossoms may not be affected by pseudomonads in general, and we should not expect enhanced growth or spread of this antagonist as a result of suppression of these epiphytes by streptomycin, at least when C9-1S is applied prior to full bloom (27). This conclusion, however, is specific to strain C9-1S, because growth of other strains of bacterial antagonists could be affected by indigenous competitors $(37,38)$. From a grower perspective, the streptomycin treatment provided an indirect assessment of the value of tank-mixing streptomycin with C9-1S for fire blight control. Mixed suspensions of streptomycin and the bacterial antagonist, Pseudomonas fluorescens strain A506, have become common industry practice in the western United States $(7,15)$ owing to occurrence of strep-

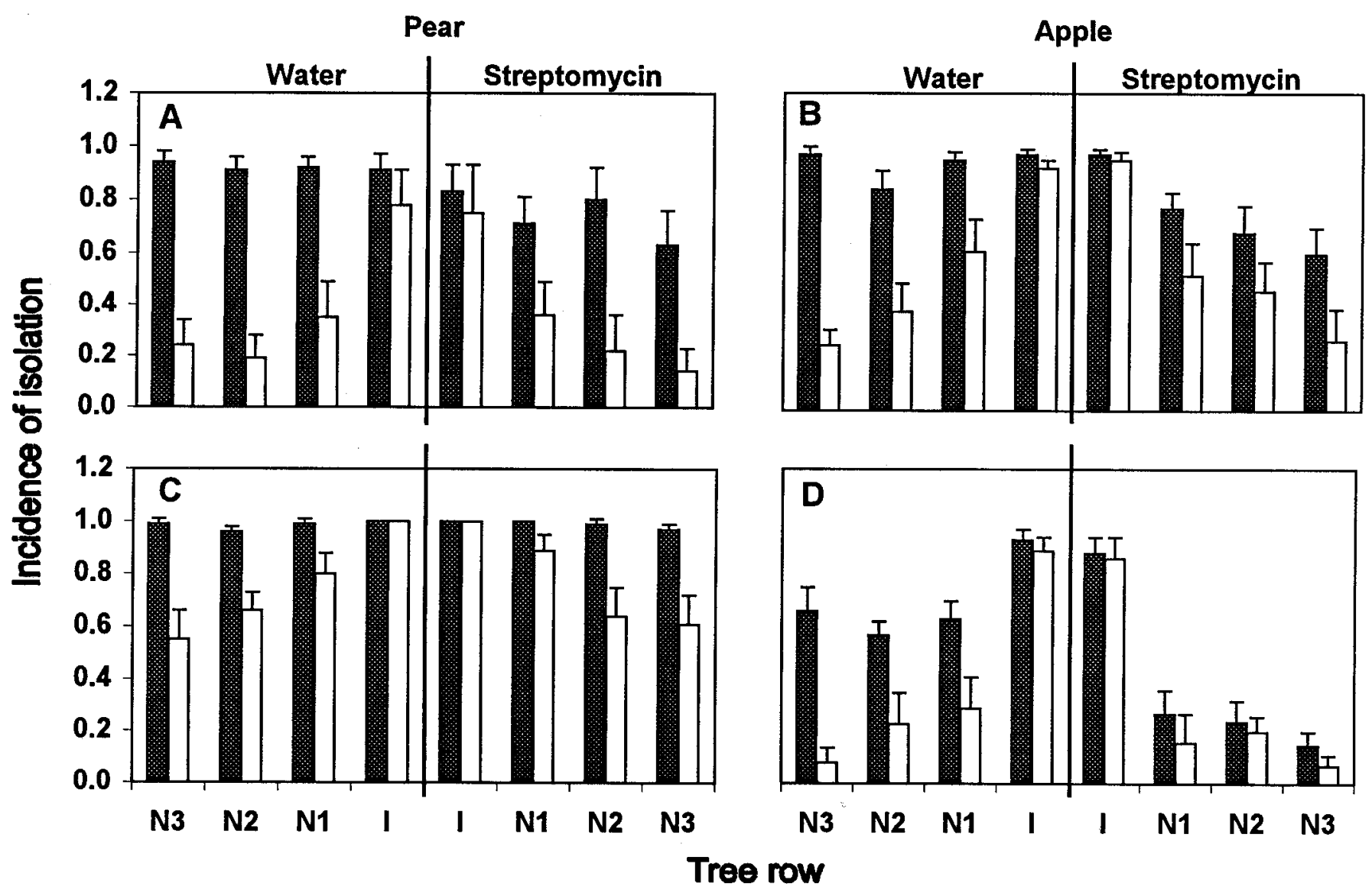

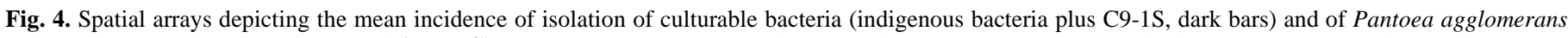

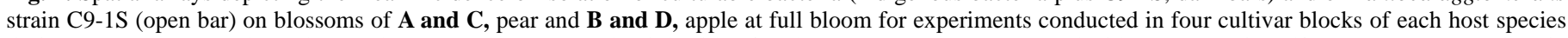

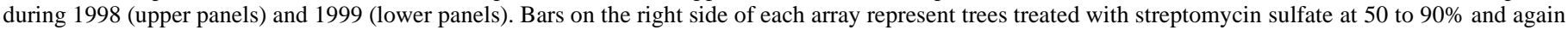

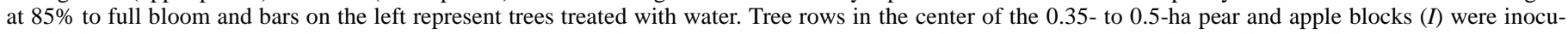

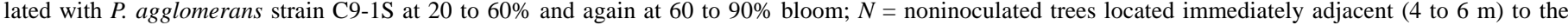

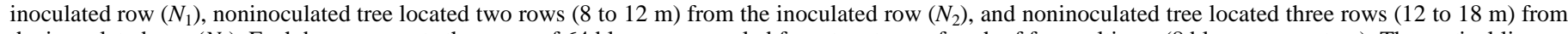

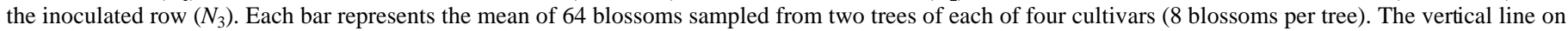
the top of each bar represents one standard error of the mean. 

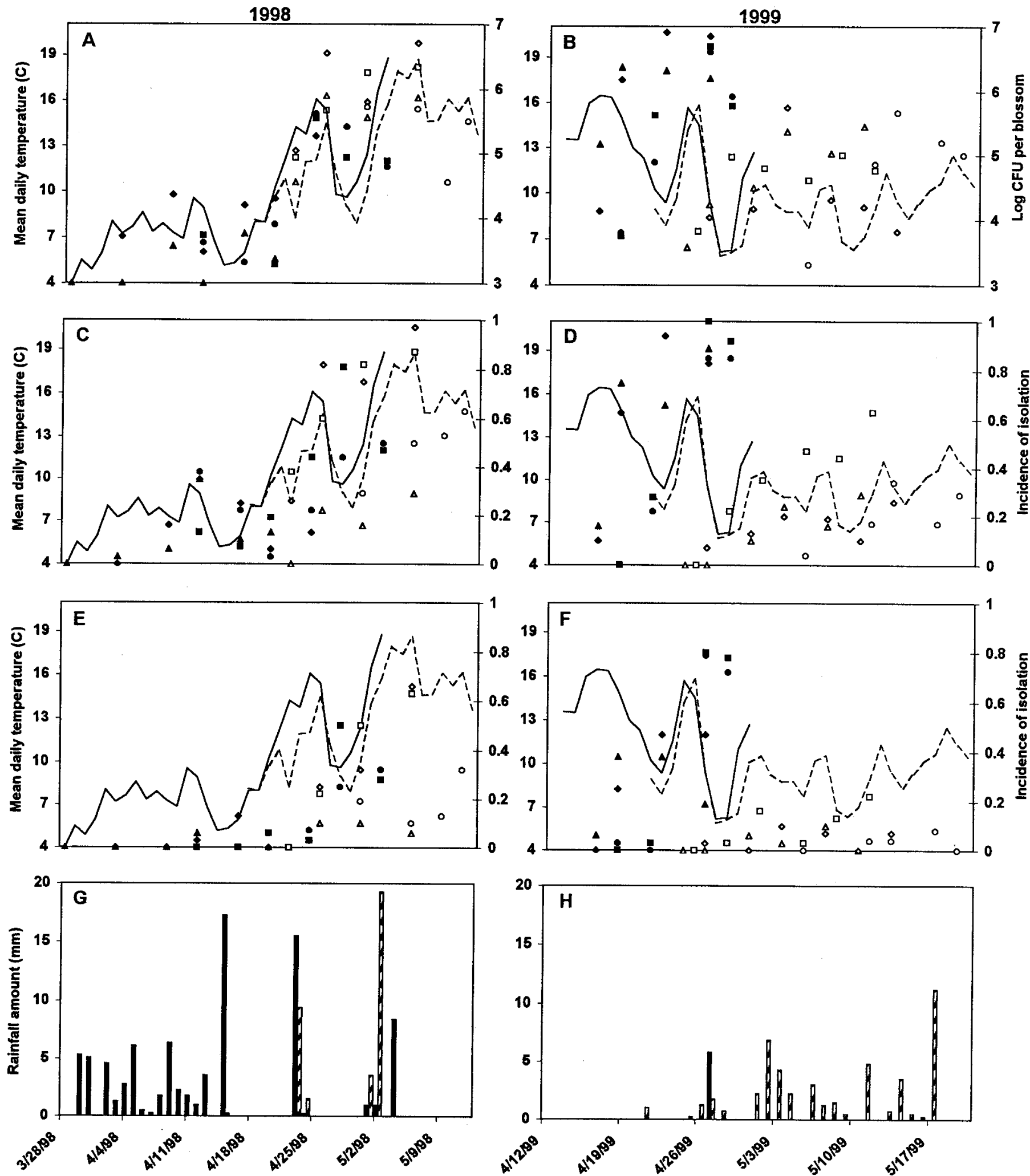

Date

Fig. 5. A through F, Mean daily temperature (lines) and $\mathbf{G}$ through $\mathbf{H}$, frequency and amount of rainfall (bars) at Medford (solid lines and bars) and Corvallis (dashed lines and bars), Oregon during pear and apple bloom of 1998 and 1999 compared to A and B, mean size of detectable populations of Pantoea agglomerans strain C9-1S on blossoms sampled from pear and apple trees inoculated with this bacterium (points) and $\mathbf{C}$ through $\mathbf{F}$, incidence of isolation of C9-1S on blossoms sampled from non-inoculated trees (points). Tree rows in the center of 0.35- to 0.5-ha blocks of pear and apple were inoculated with $P$. agglomerans strain C9-1S at 20 to $60 \%$ and again at 60 to $90 \%$ bloom. C and D, noninoculated trees located immediately adjacent (4 to $6 \mathrm{~m})$ to the inoculated row $\left(N_{1}\right) ; \mathbf{E}$ and $\mathbf{F}$, noninoculated tree located three rows $(12$ to $18 \mathrm{~m})$ from the inoculated row $\left(N_{3}\right)$. Identical symbols represent multiple samples from within the same cultivar: d'Anjou ( $(\boldsymbol{\Delta})$, Bartlett $(\diamond)$, Bosc $(\boldsymbol{\square})$ and Comice pear $(\bullet)$, and Braeburn $(\Delta)$, Golden Delicious $(\diamond)$, Jonathan/Red Delicious $(\square)$, and Red Rome apple $(\bigcirc)$. Each point represents the mean of 32 blossoms sampled from four trees of each cultivar ( 8 blossoms per tree). 
tomycin-resistant strains of E. amylovora $(16,19,28)$. The results of this study and a previous study (25) showing no adverse effect of streptomycin on colonization of blossoms by C9-1S supports the use of chemical and bacterial mixtures as a strategy to integrate two methods of control; however, this study indicated that tank mixes of streptomycin and C9-1S should not be justified on the grounds that establishment and subsequent spread of the antagonist will be improved.

Temperature was an important factor accounting for variation in size of detectable populations of C9-1S on inoculated trees and in the incidence of isolation of the antagonist from noninoculated trees. Based on these results and other observations $(9,22,26)$, we propose that temperature affects the blossom-to-blossom spread of bacterial antagonists in three ways: first, by regulating bacterial growth rate and, thus, the size of the source population; second, by regulating the amount of insect activity in an orchard; and third, by regulating rates of antagonist establishment at new sites.
The magnitude of relative area under curve for size of detectable populations of C9-1S on inoculated trees, a measure of bacterial growth and persistence after inoculation, was one to two log units higher in orchard blocks that accumulated the most degree hours during bloom compared to those that accumulated the least (Fig. 6A). On insect activity, previous research has shown that honey bees can be important vectors for introducing both $E$. amylovora and antagonistic bacteria into pear and apple flowers $(4,8,10$, 30,33 ), and that antagonistic bacteria can be recovered in high frequency from honey bees that have foraged on trees inoculated with these organisms (22; K. Johnson, unpublished data). In the orchard blocks used in this study, we observed that bee foraging activity was much greater during periods of warm weather than in cool weather (an exception to this was the 3-year-old Braeburn apple block in 1998, where very few bees were observed foraging on the young trees in spite of warm conditions, and little spread of C9-1S was observed) (Fig. 5). Thus, the warm, dry conditions that
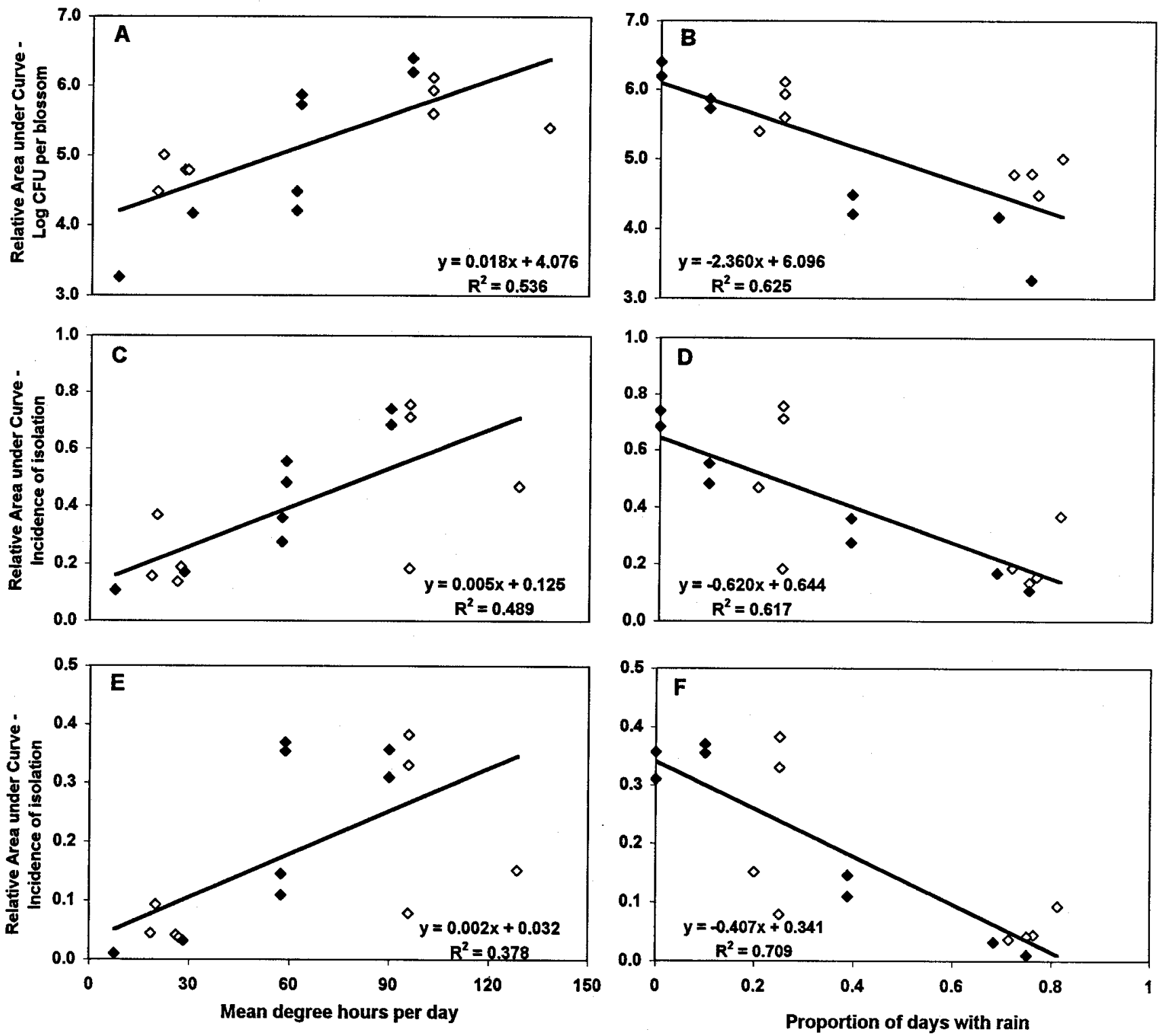

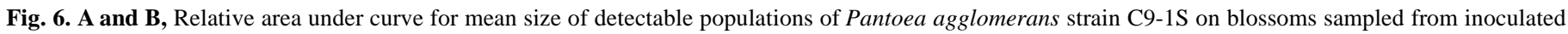

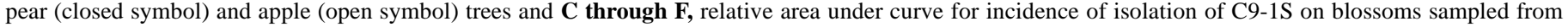

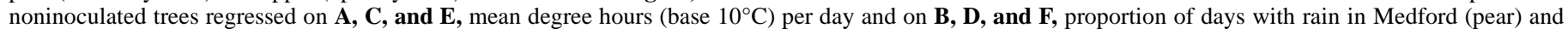

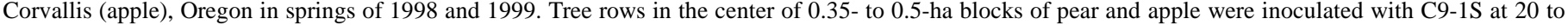

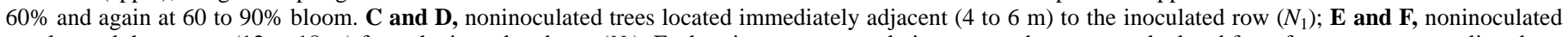

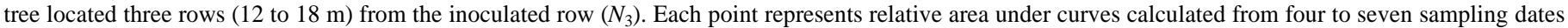
per cultivar, 32 blossoms per sample date. All regression lines were significant at $P=0.05$. 
occurred during bloom of apple in 1998 and of pear in 1999 allowed for the development of large source populations on colonized blossoms and frequent bacterial transfer among blossoms by bees or other insects. The third conclusion, that temperature also regulates rates of establishment of antagonists on previously noncolonized blossoms, is more speculative. Upper et al. (32), in a study of spread of $P$. syringae pv. syringae in bean phyllospheres, concluded that spread to previously noncolonized sites was greatest during periods when environmental conditions favored bacterial growth. In addition to growth rate, cell motility is another temperature-dependent process that may be involved with establishment of bacterial epiphytes on foliar surfaces (3).

The conclusion that blossom-to-blossom spread of C9-1S is regulated by temperature also is supported by epidemiological studies of fire blight. The frequency of detection of E. amylovora on pear and apple blossoms is correlated positively with temperature $(31,39)$, an association that has led to the development of models that assess the risk of disease based on observed weather conditions $(23,24,31)$. Our data indicate that similar models could be developed to predict the relative favorability of an orchard for growth and spread of C9-1S, which could potentially improve recommendations for optimal timing of antagonist inoculations. These recommendations, however, would need to use expected (forecasted) temperature data, because preemptive establishment of antagonists on blossoms prior to arrival of E. amylovora is essential for effective control $(7,35,36)$.

In contrast to the apparent relationship between temperature and spread of C9-1S, rain did not enhance the rate of antagonist spread and, in fact, the proportion of days with rain during bloom was correlated negatively with the size of the detectable antagonist population on inoculated trees and the incidence of isolation of the antagonist from noninoculated trees. Although it is generally accepted that rain is an important agent for dissemination of bacterial pathogens $(1,2,12,18,20)$, the precipitation events observed in this study occurred during relatively cool periods such that the variable, proportions of days with rain, also was correlated negatively with mean degree hours during bloom $(r=-0.82)$. Spring precipitation events along the Pacific Coast of the United States are typically associated with onshore movement of cold, unstable air masses that create periods of light to moderate rain with little wind. With regard to bacterial epiphytes of pear and apple, the net effect of these precipitation events appears to be a reduction in size of source populations on colonized flowers (owing to washing of bacteria from blossoms by rain), which, in combination with cold temperatures, slows the rate of increase of bacterial population size and reduces the activity of foraging insects; both factors consequently diminish the rates of bacterial movement from blossom to blossom. In previous studies of bacterial dispersal from leaf surfaces by water splash, investigators concluded that rain is an efficient means of removing bacteria from foliar surfaces $(2,12)$, and that most bacteria removed by rain disperse only short distances $(2,20)$ and are deposited on soil $(2,12)$. In contrast, MacManus and Jones (18) concluded that wind-driven rain was the most important factor involved in spreading of E. amylovora after late-spring detection of fire blight in Michigan apple nurseries. Consequently, our conclusions on the importance of rain to spread of C9-1S among blossom populations should be considered regional until additional data are available to evaluate effects of rain at a greater number of locations, and independently of temperature.

In summary, the experimental design employed in this study provided sufficient variation in environment and in measured bacterial responses to assess the relative importance of several factors on growth and spread of C9-1S on and among pear and apple blossoms. Immediately after spraying, C9-1S was detected principally on blossoms sampled from inoculated trees but, as bloom progressed, high proportions of blossoms colonized by C9-1S occurred on trees up to $18 \mathrm{~m}$ from inoculated trees. Variation in growth and spread of C9-1S was influenced by environmental conditions but not by the host species supporting its growth. Streptomycin sulfate suppressed populations of indigenous bacterial epiphytes in three of four experiments but, compared with treatment with water, did not affect incidence of isolation, size of detectable populations, or spread of C9-1S in any experiment. As with E. amylovora, blossom-to-blossom spread of Pantoea agglomerans strain C9-1S was favored by periods of warm, dry weather, and was limited when conditions were cooler and wetter.

\section{ACKNOWLEDGMENTS}

Oregon Agricultural Experiment Station Technical Paper 11,701. We thank the Winter Pear Control Committee and the USDA NRICGP for their support.

\section{LITERATURE CITED}

1. Agrios, G. N. 1997. Plant Pathology, 4th ed. Academic Press, San Diego, CA.

2. Butterworth, J., and McCartney, H. A. 1991. The dispersal of bacteria from leaf surfaces by water splash. J. Appl. Bacteriol. 71:484-496.

3. Haefele, D. M., and Lindow, S. E. 1987. Flagellar motility confers epiphytic fitness advantages upon Pseudomonas syringae. Appl. Environ. Microbiol. 53:2528-2533.

4. Hildebrand, E. M., and Phillips E. F. 1936. The honeybees and the beehive in relation to fire blight. J. Agric. Res. 52:789-810.

5. Hirano, S. S., Nordheim, E. V., Arny, D. C., and Upper, C. D. 1982. Lognormal distribution of epiphytic bacterial populations on leaf surfaces. Appl. Environ. Microbiol. 44:695-700.

6. Ishimaru, C. A., Klos, E. J., and Brubaker, R. R. 1988. Multiple antibiotic production by Erwinia herbicola. Phytopathology 78:746-750.

7. Johnson, K. B., and Stockwell, V. O. 1998. Management of fire blight: A case study in microbial ecology. Annu. Rev. Phytopathol. 36:227-248.

8. Johnson, K. B., Stockwell, V. O., Burgett, D. M., Sugar, D., and Loper, J. E. 1993. Dispersal of Erwinia amylovora and Pseudomonas fluorescens by honey bees from hives to apple and pear blossoms. Phytopathology 83:479-484.

9. Johnson, K. B., Stockwell, V. O., McLaughlin, M. J., Sugar, D., Loper, J. E., and Roberts, R. G. 1993. Effect of bacterial antagonists on establishment of honey bee-dispersed Erwinia amylovora in pear blossoms and on fire blight control. Phytopathology 83:995-1002.

10. Kiett, G. W., and Ivanoff, S. S. 1941. Transmission of fire blight by bees in relation to nectar concentration of apple and pear blossoms. J. Agric. Res. 62:745-753.

11. King, E. O., Ward, M. K., and Raney, D. E. 1954. Two simple media for the demonstration of pyocyanin and fluorescein. J. Lab. Clin. Med. 44:301-307.

12. Lindemann, J., and Upper, C. D. 1985. Aerial dispersal of epiphytic bacteria over bean plants. Appl. Environ. Microbiol. 50:1229-1232.

13. Lindow, S. E. 1985. Integrated control and role of antibiosis in biological control of fire blight and frost injury. Pages 83-115 in: Biological Control on the Phylloplane, C. E. Windels and S. E. Lindow, eds. The American Phytopathological Society, St. Paul, MN.

14. Lindow, S. E. 1993. Population dynamics of Pseudomonas fluorescens strain A506 in pear flowers following inoculation. (Abstr.) Phytopathology 83(suppl.):S1339.

15. Lindow, S. E., McGourty, G., and Elkins, R. 1996. Interactions of antibiotics with Pseudomonas fluorescens A506 in the control of fire blight and frost injury of pear. Phytopathology 86:841-848.

16. Loper, J. E., Henkels, M. D., Roberts, R. G., Grove, G. G., Willet, M. J., and Smith, T. J. 1991. Evaluation of streptomycin, oxytetracycline, and copper resistance of Erwinia amylovora isolated from pear orchards in Washington state. Plant Dis. 75:287-290.

17. Loper, J. E., Suslow, T. V., and Schroth, M. N. 1984. Lognormal distribution of bacterial populations in the rhizosphere. Phytopathology 74:1454-1460.

18. McManus, P. S., and Jones, A. L. 1994. Role of wind driven rain, aerosols, and contaminated budwood in incidence and spatial pattern of fire blight in an apple nursery. Plant Dis. 78:1059-1066.

19. Moller, W. J., Schroth, M. N., and Thomson, S. V. 1981. The scenario of fire blight and streptomycin resistance. Plant Dis. 65:563-568.

20. Mundt, C. C., Ahmed, H. U., Finckh, M. R., Nieva, L. P., and Alfonso, R. F. 1999. Primary disease gradients of bacterial blight of rice. Phytopathology 89:64-67.

21. Nuclo, R. L. 1997. Natural spread of and competition between two bacterial antagonists of the fire blight pathogen, Erwinia amylovora, on blossoms of 
Bartlett pear. M.Sc. thesis, Oregon State University, Corvallis.

22. Nuclo, R. L., Johnson, K. B., Stockwell, V. O., and Sugar, D. 1997. Secondary colonization of pear blossoms by two bacterial antagonists of the fire blight pathogen. Plant Dis. 82:661-668.

23. Smith, T. J. 1996. A risk assessment model for fire blight of apple and pear. Acta Hortic. 411:97-104.

24. Steiner, P. W. 1990. Predicting apple blossom infections by Erwinia amylovora using the MARYBLYT model. Acta Hortic. 273:139-148.

25. Stockwell, V. O., Johnson, K. B., and Loper, J. E. 1996. Compatibility of bacterial antagonists of Erwinia amylovora with antibiotics used to control fire blight. Phytopathology 86:834-840.

26. Stockwell, V. O., Johnson, K. B., and Loper, J. E. 1998. Establishment of two bacterial antagonists of Erwinia amylovora on pear and apple blossoms as influenced by inoculum preparation. Phytopathology 88:506-513.

27. Stockwell, V. O., McLaughlin, R. J., Henkels, M. D., Loper, J. E., Sugar, D., and Roberts, R. G. 1999. Epiphytic colonization of pear stigmas and hypanthia by bacteria during primary bloom. Phytopathology 89:11621168.

28. Stockwell V. O., Sugar, D., Spotts, R., Johnson, K. B., and Loper, J. E. 1996. Recovery of streptomycin-resistant isolates of Erwinia amylovora from Oregon orchards. (Abstr.) Phytopathology 86(suppl.):S50.

29. Thomson, S. V. 1986. The role of the stigma in fire blight infections. Phytopathology 76:476-482.

30. Thomson, S. V., Hansen, D. R. Flint, K. M., and Vandenberg, J. D. 1992. Dissemination of bacteria antagonistic to Erwinia amylovora by honey bees. Plant Dis. 76:1052-1056.
31. Thomson, S. V., Schroth, M. N., Moller, W. J., and Reil, W. O. 1982. A forecasting model for fire blight of pear. Plant Dis. 66:576-579.

32. Upper, C. D., Reid, K. K., Clayton, M. K., and Hirano, S. S. 1999. Scale and growth factors in spread of $P$. syringae pv. syringae in the bean phyllosphere. (Abstr.) Phytopathology 89(suppl.):S79.

33. van Laere, O., De Greef, M., and De Wael, L. 1981. Influence of the honey bee on fire blight transmission. Acta Hortic. 117:131-141.

34. Vanneste, J. L. 1996. Honey bees and epiphytic bacteria to control fire blight, a bacterial disease of apple and pears. Biocon. News Inform. 17:67-78.

35. Wilson, M., Epton H. A. S., and Sigee, D. C. 1992. Interactions between Erwinia herbicola and E. amylovora on the stigma of hawthorn blossoms. Phytopathology 82:914-918.

36. Wilson, M., and Lindow, S. E. 1993. Interactions between the biological control agent Pseudomonas fluorescens strain A506 and Erwinia amylovora in pear blossoms. Phytopathology 83:117-123.

37. Wilson, M., and Lindow, S. E. 1994. Ecological similarity and coexistence of epiphytic ice-nucleating (Ice+) Pseudomonas syringae strains and a non-ice-nucleating (Ice-) biological control agent. Appl. Environ. Microbiol. 60:3128-3137.

38. Wilson, M., and Lindow, S. E. 1994. Coexistence among epiphytic bacterial populations mediated through nutritional resource partitioning. Appl. Environ. Microbiol. 60:4468-4477.

39. Zoller, B. G., and Sisevich, J. 1979. Blossom populations of Erwinia amylovora in pear orchards vs accumulated degree hours over 18.3 Celcius. (Abstr.) Phytopathology 69(suppl.):S1050. 